Article

\title{
Investigation on Interface Damage between Cement Concrete Base Plate and Asphalt Concrete Waterproofing Layer under Temperature Load in Ballastless Track
}

\author{
Xianhua Chen ${ }^{1, * \mathbb{D}}, \mathrm{Yu} \mathrm{Zhu}^{1}$, Degou Cai ${ }^{2}$, Gang Xu ${ }^{1}$ and Tao Dong ${ }^{3}$ \\ 1 School of Transportation, Southeast University, Nanjing 211189, China; zhuyuJS@126.com (Y.Z.); \\ xugang619@hotmail.com (G.X.) \\ 2 China Academy of Railway Sciences Corporation Limited Railway Engineering Research Institute, \\ Beijing 100081, China; caidegou@126.com \\ 3 JiangSu Yangtze River Expressway Company Limited, Wuxi 214000, China; 15050580576@163.com \\ * Correspondence: chenxh@seu.edu.cn
}

Received: 5 March 2020; Accepted: 10 April 2020; Published: 12 April 2020

\begin{abstract}
The interfacial bond between cement concrete base plate (CCBP) and asphalt concrete waterproofing layer (ACWL) is a weak portion in the newly developed Chinese high-speed railway ballastless track. The interface damage caused due to fluctuating temperature load and dynamic train load is one of the most critical problems in Northern China. This paper aims to investigate the interface damage evolution process under temperature load via experimental and simulation analysis. Full-scale transverse shear tests were performed to explore the interface bond-slip mode of the adjacent ACWL and CCBP. Then, a finite element model of a ballastless track structure was built and a cohesive zone model (CZM) was utilized to model the interface damage initiation, crack propagation, and delamination process under uniform/gradient temperature load. Furthermore, the dynamic response of the ballastless track where CCBP and ACWL were partly/totally debonded was investigated and compared with the perfectly bonded structure. The results demonstrate that bilinear CZM is capable of revealing the interface damage initiation, crack propagation, and delamination process under temperature load. The interface state between the adjacent CCBP and ACWL was greatly affected by temperature changes and the interface bonding state had a great impact on the dynamic response of ballastless track.
\end{abstract}

Keywords: ballastless track; asphalt concrete waterproofing layer; interface damage; CZM

\section{Introduction}

Asphalt concrete has been tentatively used for a full-cross-section waterproofing layer in the substructure of ballastless track in China [1,2]. Asphalt concrete has also been employed as an isolation layer of the high-speed railway foundation, sub-ballast layer of ballast railway, or reinforcement layer of the railway subgrade in Germany, Japan, France, Italy, etc. [3-7]. Compared with cement concrete, which is brittle and prone to crack in cold regions, asphalt concrete has the advantages of waterproofing, anti-cracking ability, vibration reduction, and deformation coordination with the subgrade $[8,9]$. The accumulation of water in the subgrade can lead to subgrade strength decrease and subgrade settlement. In seasonally frozen regions, the frost heave of the accumulated water in subgrade will cause uneven deformation. Thus, asphalt concrete with good anti-cracking performance is conducive to the integrity and stability of ballastless track [10-12]. The high-speed railway development offers a broad application market for asphalt concrete. 
The designer of the high-speed railway usually treats the under-rail structure as a completely continuous state. In other words, slippage or debonding is not allowed between adjacent layers $[13,14]$. As a layered structure composed of track-slab, cement concrete base plate (CCBP), asphalt concrete waterproofing layer (ACWL), and cement concrete base or supporting layer, the adjacent layers in the ballastless track subgrade are bonded by the interfacial adhesion force which is much smaller than the strength of the concrete layers $[15,16]$. In this regard, the interface is the weakest part of the whole structure. The stiffness difference between asphalt concrete and cement concrete will lead to the inconsistent deformation trend of the adjacent CCBP and ACWL under train dynamic loads, and thus, interface shear stress can be generated. Repeated shear action on the interface between CCBP and ACWL will cause the initiation of interface stress. In Northern China, the annual temperature difference is high, and the temperature changes rapidly in spring and autumn. For example, in Harbin the annual temperature difference exceeds $50^{\circ} \mathrm{C}$ and the daily temperature difference is about $15^{\circ} \mathrm{C}$ in winter. The air temperature changes will cause temperature changes in the ballastless track, and concrete materials tend to deform under temperature loads [17]. The thermal expansion coefficients of asphalt concrete and cement concrete are different, and hence, interface shear stress can be generated by the temperature-stress difference between the adjacent CCBP and ACWL under the fluctuating temperature load [18-20]. The interface damage accumulates under the cyclic temperature loads and the propagation process of interface cracks is accelerated because of train dynamic loads. The interface cracks offer entry channels for rainwater to infiltrate into the subgrade body which can result in serious freeze-thaw damage in cold regions [21]. The interface cracks can not only weaken the entire structural integrity of the ballastless track subgrade, but also reduce the running stability and derailment safety of the high-speed railway. Therefore, the high-speed railway engineers have paid great attention to the interface safety of the ballastless track and have conducted several research works on the interface delamination mechanism of the typical track subgrade structure [14-16,21]. But there has been almost no research on the interface damage of the novel ballastless structure which utilizes ACWL under fluctuating temperature loads and train dynamic loads.

The combination of laboratory and field full-scale shear tests and finite element numerical simulations offers excellent possibilities for investigation of the interface properties of layered structures. Shen et al. [22] analyzed the tensile splitting strength, crack initiation load, and damage characteristics of the composite samples of different types of concrete based on the tensile splitting tests. Dai et al. [14] explored the transverse and longitudinal interfacial shear capacity of full-scale prefabricated standard track slabs and discussed the interfacial bond-slip law of continuous slab track based on the full-scale field shear tests of ballastless track. Cao et al. [23] studied the interface damage mechanism of slab track under the coupling effect of train load and water by embedding the quarter-points elements at the crack tip. Zhu et al. [24] numerically analyzed the interface damage occurring between the prefabricated slab and cement asphalt mortar layer in CRTS-II (China Railway Track System type II) ballastless slab track by utilization of non-linear cohesive elements at the interface in the finite element model of the track system. The interface damage, crack, and delamination process under the combined action of temperature loads and train dynamic load was investigated and the results indicate that a cohesive zone model $(\mathrm{CZM})$ is capable of predicting the interface damage propagation process.

The objective of the current work is to study the interface bond-slip process of the adjacent CCBP and ACWL in the ballastless track subgrade under temperature loads and dynamic train loads based on the crack parameters of CZM obtained from field transverse shear tests. Firstly, full-scale transverse shear tests were conducted to explore the interface bond-slip mode and obtain the interface crack parameters between CCBP and ACWL. The suitability of bilinear CZM in revealing the interface damage propagation was verified by comparing the experimental and simulation results of full-scale transverse shear tests. Then, a 3D finite model of a new ballastless track structure which utilizes the full-cross section ACWL was built in ABAQUS to model the interface damage initiation, crack propagation, and delamination process under uniform and gradient temperature loads. The effects of interface parameters including interfacial shear strength, interfacial shear stiffness, and critical fracture 
energy on the damage propagation process were explored. Finally, the dynamic responses of new ballastless track structure containing slight and severe interface damage were analyzed.

\section{Experiment and Computing CZM Parameters}

\subsection{Cohesive Zone Model}

In this paper, a bilinear CZM was applied to analyze the interface damage between CCBP and ACWL. The relationship between stress and displacement for the bilinear traction-separation law is plotted in Figure 1. During the interface damage evolution process, the interface stress $t$ increases gradually to the maximum value $t^{0}$, and then interface damage initiates. After interface damage initiation, the interface stress decreases gradually. The interface cohesive element completely fails when the maximum displacement $\delta^{f}$ is attained. The area under the stress-displacement curve is critical fracture energy $G^{C}$.

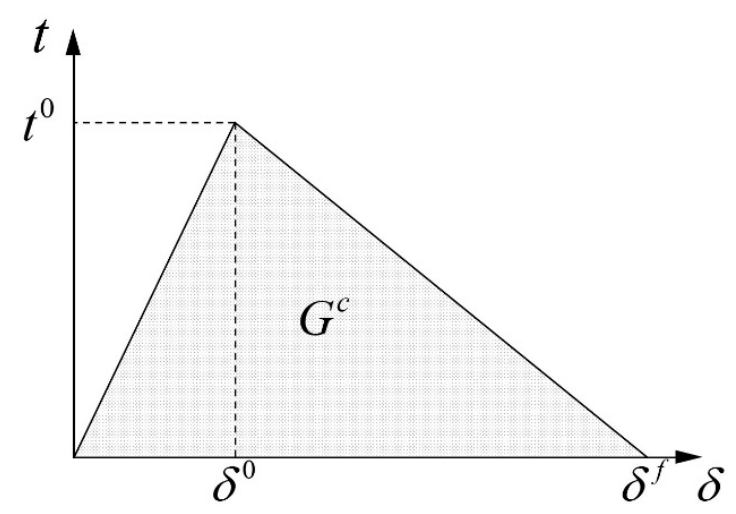

Figure 1. Stress-displacement curve of bilinear traction-separation law.

Initiation of interface damage is judged by the quadratic nominal stress criterion. As defined in Equation (1), the interfacial initiates when the quadratic interaction function reaches 1.

$$
\left\{\frac{\left\langle t_{n}\right\rangle}{t_{n}^{0}}\right\}^{2}+\left\{\frac{\left\langle t_{s}\right\rangle}{t_{s}^{0}}\right\}^{2}+\left\{\frac{\left\langle t_{t}\right\rangle}{t_{t}^{0}}\right\}^{2}=1
$$

where $t_{n}, t_{s}, t_{t}$ represent the normal stress, shear stress in the first and second direction, separately, $t_{n}^{0}$ is the tensile strength, $t_{s}^{0}, t_{t}^{0}$ are the shear strength in the first and second direction, respectively, and $\langle\cdot\rangle$ is the Macaulay bracket, which means that no damage will initiate in the pure compression state.

The fracture toughness, which is the area under the stress-displacement curve, is used as the crack propagation criterion of the cohesive element. The failure criterion adopted in this paper can be expressed as following:

$$
\left\{\frac{G_{n}}{G_{n}^{C}}\right\}^{2}+\left\{\frac{G_{s}}{G_{s}^{C}}\right\}^{2}+\left\{\frac{G_{t}}{G_{t}^{C}}\right\}^{2}=1
$$

where $G_{n}, G_{s}, G_{t}$ are energy produced in the normal, the first, and the second shear directions, respectively, and $G_{n}^{C}, G_{s}^{C}, G_{t}^{C}$ are the critical fracture energy required to cause debond failure in the normal, the first, and the second shear directions, respectively. Two damage variables in ABAQUS used to describe the failure process of interface cohesive element are QUADSCRT and SDEG [25]. QUADSCRT and SDEG are dimensionless variables and the in between ranges are $0 \sim 1$. When QUADSCRT reaches 1 , the microcracks expand into macroscopic cracks. When the value of SDEG reaches 1 , the interface completely delaminates. 


\subsection{Full-Scale Transverse Shear Test and Parameter Computation}

As it is difficult to implement the temperature load in full-scale transverse shear tests, the interface characteristics were analyzed by applying the transverse horizontal load to the cement concrete base plate in the composite plate, because the interaction mechanism of the two loading modes is same. The China Academy of Railway Science and Southeast University conducted field full-scale transverse shear tests on the interface characteristics between the asphalt concrete foundation and cement concrete base plate.

A cement concrete base plate with dimensions of length $19.2 \mathrm{~m}$, width $3.4 \mathrm{~m}$, and height $0.3 \mathrm{~m}$ was constructed on the asphalt concrete foundation. The interface bonding strength was created by the cement hydration reaction. The experimental setup was composed of a cement concrete base plate, an asphalt concrete foundation, counterforce piers, hydraulic jacks, dynamometers, and displacement meters (see Figure 2). During the test, the transverse horizontal load was applied to the base plate by hydraulic jacks (see Figure 3a), and the relative displacement between the base plate and asphalt concrete foundation was measured using displacement meters (see Figure $3 b$ ). Ten counterforce piers $(1 \mathrm{~m} \times 1 \mathrm{~m} \times 1 \mathrm{~m})$ were placed at every $1 \mathrm{~m}$ in one line on the lateral side of the asphalt concrete foundation. Hydraulic jacks were installed between the slab plate and counterforce piers. They were controlled via an automation system and worked synchronously.

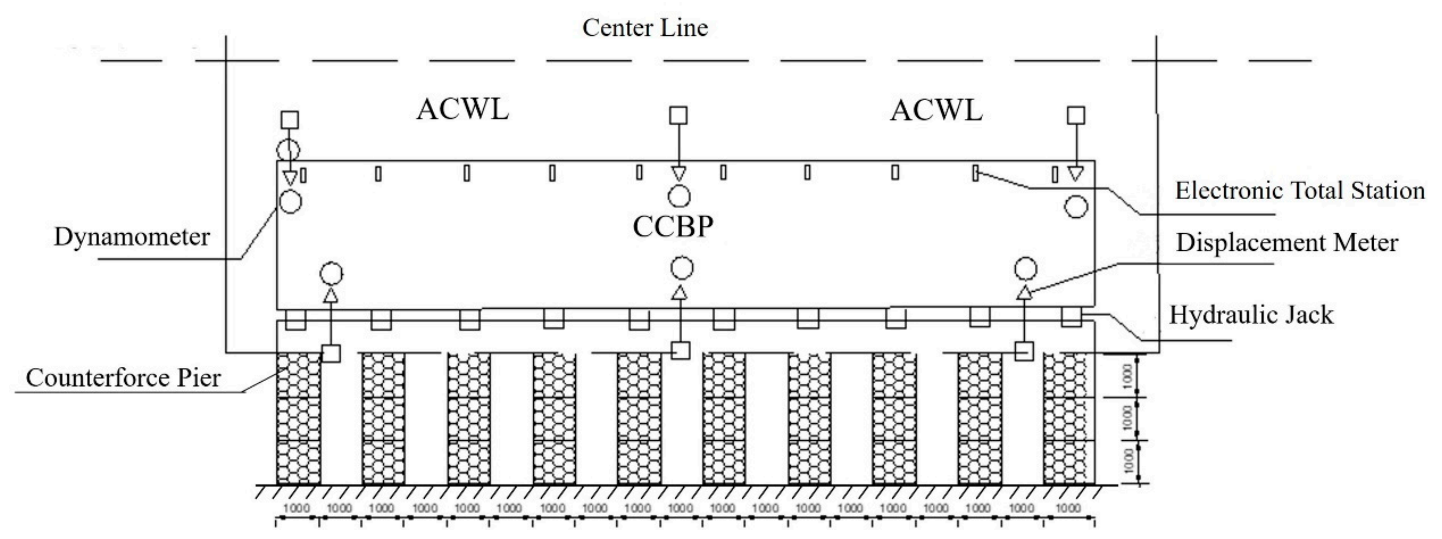

Figure 2. Test setup of full-scale plate-pushing test. CCBP: cement concrete base plate. ACWL: asphalt concrete waterproofing layer.

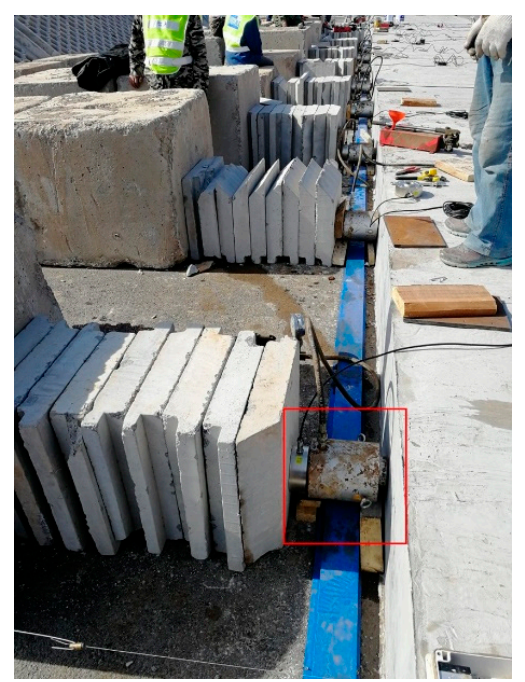

(a)

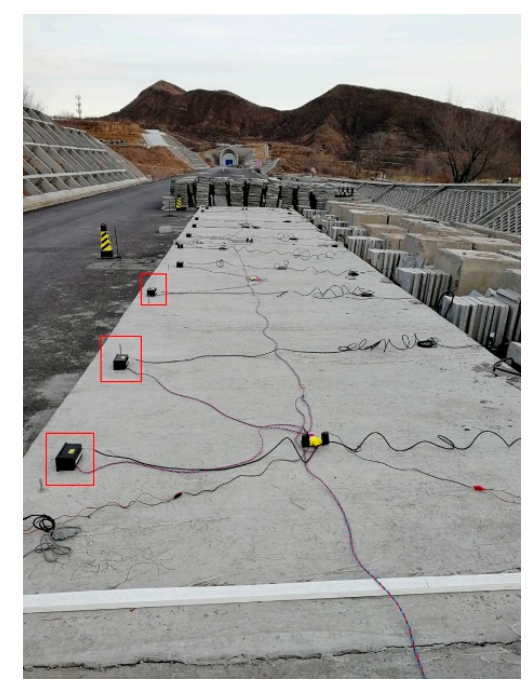

(b)

Figure 3. Full-scale transverse shear test site displacement meters.

(a) Layout of hydraulic jacks; (b) Layout of 
Two relative control points were established on the plain stage of the slope beside the track slab to ensure the relative accuracy of the control network. The lateral displacement monitoring points are marked in Figure 2. The stepwise loading method was adopted. Half a ton was loaded per stage until the total load reached 5 tons, and then, 0.2 ton per stage was added until the interface was debonded. The shear stress-displacement monitoring curve is plotted in Figure 4.

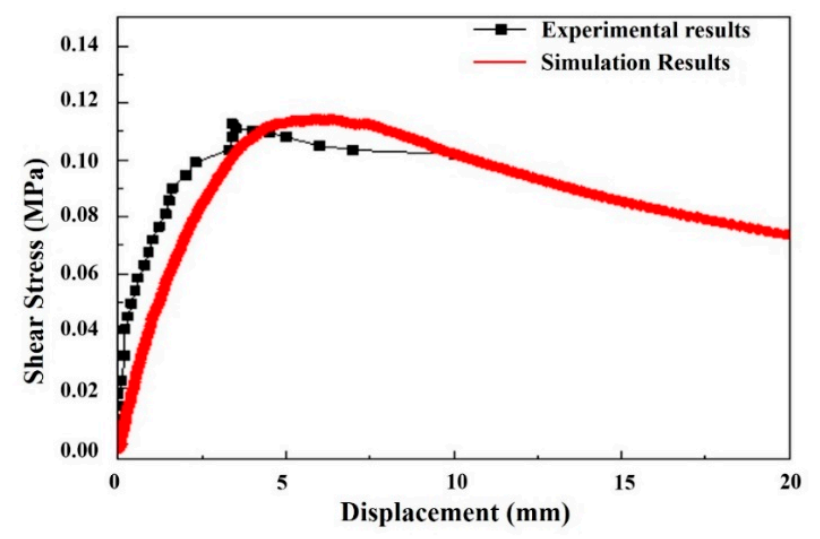

Figure 4. Comparison of simulation and experiment results.

The parameters of cohesive element in ABAQUS include interfacial shear strength $t^{0}$, interfacial shear stiffness $k$, and critical fracture energy $G^{C}$. As shown in Figure 1, interfacial shear stiffness and critical fracture energy can be expressed as:

$$
\begin{gathered}
k=\frac{t^{0}}{\delta^{0}} \\
G^{C}=\int_{0}^{\delta^{f}} t(\delta) d \delta=\frac{1}{2} t^{0} \delta^{f}
\end{gathered}
$$

where $\delta^{0}$ is the critical displacement, and $\delta^{f}$ is the maximum displacement. $\tau^{0}, \delta^{0}$, and $\delta^{f}$ are obtained from field experiments. In order to obtain $G^{C}$, the force-displacement curve from the field test is extended with the original slope to intersect the horizontal axis. The CZM parameters obtained from the full-scale transverse shear test are listed in Table 1.

Table 1. Parameters of the cohesive zone model (CZM).

\begin{tabular}{cccc}
\hline Temperature $\left({ }^{\circ} \mathbf{C}\right)$ & $\begin{array}{c}\text { Interfacial Shear } \\
\text { Strength } t^{0}(\mathbf{M P a})\end{array}$ & $\begin{array}{c}\text { Interfacial Shear } \\
\text { Stiffness } k \mathbf{M P a} / \mathbf{m m})\end{array}$ & $\begin{array}{c}\text { Critical Fracture Energy } \\
G^{C}\left(\mathbf{m J} / \mathbf{m m}^{2}\right)\end{array}$ \\
\hline 25 & 0.10 & 0.03 & 0.4 \\
\hline
\end{tabular}

\section{Numerical Simulations of Interface Damage Propagation in the Full-Scale Shear Test Specimen}

\subsection{Construction of the Finite Element Model}

To prove the feasibility of applying the CZM to analyze the interface damage between CCBP and ACWL in the ballastless track subgrade, a three-dimensional finite element model of the full-scale shear test was established. The model size, boundary conditions, and load conditions were the same as the field test. Cohesive elements with zero thickness and 8-node (COH3D8) were inserted between the adjacent CCBP and ACWL. The two layers were assumed to be linear-elastic and modeled as element C3D8R. The parameters of the CZM element were obtained from the full-scale transverse shear test: Young's modulus and the shear modulus of cohesive units were $1000 \mathrm{MPa}$ and $30 \mathrm{MPa}$, respectively. The material parameters of ACWL and CCBP are listed in Table 2. 
Table 2. Material parameters of the cement base plate and ACWL.

\begin{tabular}{cccc}
\hline Layer Type & Density $\left(\mathbf{k g} / \mathbf{m}^{\mathbf{3}}\right)$ & Young's Modulus (MPa) & Poisson's Ratio \\
\hline Cement base plate & 2300 & 28,000 & 0.18 \\
ACWL & 2400 & 4568 & 0.3 \\
\hline
\end{tabular}

\subsection{Verification of the Model for Interface Damage Simulation}

The shear stress-displacement curves of the experiment and simulation results are plotted in Figure 4. The maximum shear load obtained from the field test is about $0.112 \mathrm{MPa}$ and from the simulation result is $0.114 \mathrm{MPa}$. As shown in Figure 4, the force-displacement curves derived from the simulation and the field experiment are generally consistent with each other. The comparison results show that the numerical simulation is reliable and it is reasonable and reliable to utilize bilinear CZM in the research of the interface damage of the adjacent CCBP and ACWL in the ballastless track subgrade.

\section{Numerical Simulation of Interface Damage of Ballastless Track under Temperature Load}

\subsection{Construction of the Finite Element Model for Ballastless Track}

To investigate the interfacial bond-slip behavior of the adjacent CCBP and ACWL under temperature loads, a three-dimensional finite element model of the ballastless track structure of a high-speed railway test section in China was built up using ABAQUS software (see Figure 5). As the rails have little influence on the interface behavior between the ballastless track foundation layers under temperature loads, the rails and fasteners were not considered in this model. The model was composed of track slab, self-compacting concrete (SCC), CCBP, ACWL, road bed, and soil foundation (see Figure 6). Considering the boundary effect and computational time for mesh generation and calculations, three base plates were selected for the model. The length of each base plate was $19.2 \mathrm{~m}$ and an expansion joint measuring $0.02 \mathrm{~m}$ in width was set between the adjacent base plates. The length of the other structures under the base plates was $80 \mathrm{~m}$ in Z-direction. The geometries and material parameters of each layer are listed in Table $3[26,27]$. The CZM parameters of the interface between CCBP and ACWL were obtained from the full-scale transverse shear tests. The displacement at the bottom of the soil foundation was restricted, and four sides of the model were symmetrically constrained. Tie binding contact was applied at the interface of all the layers. The model contained 53,232 eight-node continuum elements with reduced integration (C3D8R) and 3200 eight-node cohesive elements (COH3D8). The C3D8R elements were assumed to be linear-elastic and the cohesive elements were utilized at the interface between CCBP and ACWL.

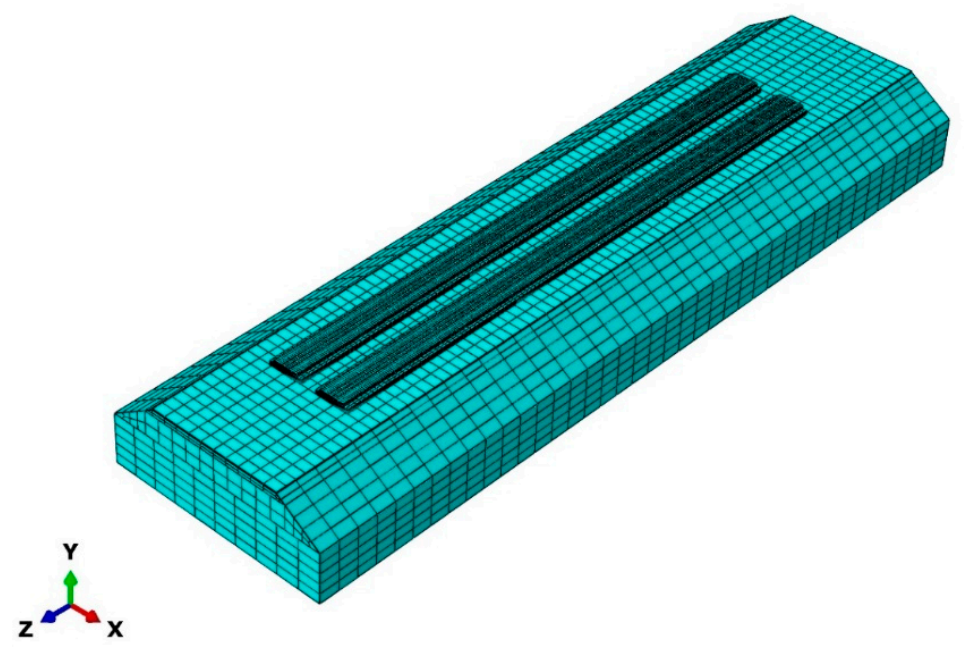

Figure 5. Model of ballastless track structure. 


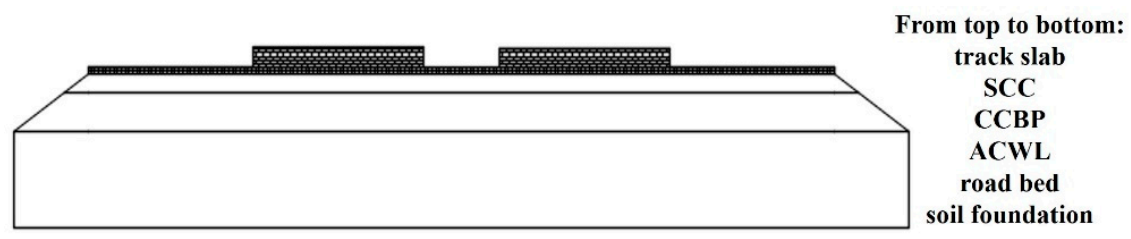

Figure 6. Sub-rail infrastructure cross-sectional picture. SCC: self-compacting concrete.

Table 3. Geometries and material parameters of ballastless track system.

\begin{tabular}{ccccccc}
\hline Components & Width $(\mathbf{m})$ & $\begin{array}{c}\text { Thickness } \\
\mathbf{( m )}\end{array}$ & $\begin{array}{c}\text { Density } \\
\mathbf{( k g / \mathbf { m } ^ { 3 } )}\end{array}$ & $\begin{array}{c}\text { Young's } \\
\text { Modulus } \\
\mathbf{( M P a )}\end{array}$ & $\begin{array}{c}\text { Poisson } \\
\text { Ratio }\end{array}$ & $\begin{array}{c}\text { Thermal } \\
\text { Expansion } \\
\text { Coefficient } \\
\left(\mathbf{C}^{-\mathbf{1}} \mathbf{)}\right.\end{array}$ \\
\hline Track slab & 2.55 & 0.2 & 2400 & 36,000 & 0.20 & $1 \times 10^{-5}$ \\
SCC & 3.40 & 0.4 & 2300 & 28,000 & 0.18 & $1.5 \times 10^{-5}$ \\
CCBP & 3.40 & 0.4 & 2300 & 28,000 & 0.18 & $1.5 \times 10^{-5}$ \\
ACWL & 13.4 & 0.1 & 2400 & 4568 & 0.3 & $2 \times 10^{-5}$ \\
Surface layer of road bed & 13.4 & 0.6 & 2200 & 160 & 0.3 & $1 \times 10^{-5}$ \\
Bottom layer of road bed & 13.4 & 2.4 & 1900 & 100 & 0.3 & $1 \times 10^{-5}$ \\
Soil foundation & 21.7 & 5 & 1850 & 60 & 0.3 & - \\
\hline
\end{tabular}

\subsection{Interface Damage Analysis under Uniform Temperature Load}

In this case, the initial temperature of each layer was the same and varied synchronously. Under uniform temperature load, the under-rail structural layers exhibited a uniform longitudinal and transverse deformation trend. As the displacements of layers were constrained and thermal expansion coefficients of asphalt concrete and cement concrete were different, there was a relative movement trend between the two layers and shear stress occurred at the interface. When shear stress exceeded the interface bonding strength, shear failure occurred at the interface and the restraint effect of ACWL on the cement base plate failed. The results of previous numerical calculations prove that the bonding performance of the interface between CCBP and ACWL is consistent with each other under the uniform rise and drop in temperature load. Therefore, herein, the evolution process of interfacial bond-slip behavior under uniform rising temperature load is analyzed.

The initial temperature was set as $15^{\circ} \mathrm{C}$, and the temperature rising ranges $(\Delta t)$ were $1,5,10,15$, 20,30 , and $40^{\circ} \mathrm{C}$, respectively. To investigate the $\Delta t$ required to achieve complete debonding state, $50^{\circ} \mathrm{C}$ and $60^{\circ} \mathrm{C}$ rising ranges were also employed. The indicators that characterized interface state included shear stress, an index for the interlayer damage initiation (QUADSCRT), and an index for damage degree (SDEG).

Figure 7 shows the contour of damage indices (QUADSCRT and SDEG) under different temperature loads. The interface damage evolution process can be divided into four stages. At the first stage $\left(\Delta t=1-5^{\circ} \mathrm{C}\right)$, damage accumulated at the interface and interface crack did not yet occur. At the second stage $\left(\Delta t=5-15^{\circ} \mathrm{C}\right)$, QUADSCRT reached 1 and interface microcracks generated at the expansion joint, but the maximum value of SDEG was still lower than 1 which meant there were no macrocracks generating at the interface. At the third stage $\left(\Delta t=15-50{ }^{\circ} \mathrm{C}\right), \mathrm{SDEG}$ at the expansion joint reached the maximum value first, and macrocracks started to generate at the expansion joint and propagated to the other areas of the interface. Finally, when the temperature rising range exceeded $60^{\circ} \mathrm{C}$, the adjacent layers were totally delaminated and interface contact state turned into sliding friction (see Figure $7 \mathrm{f}$ ). 


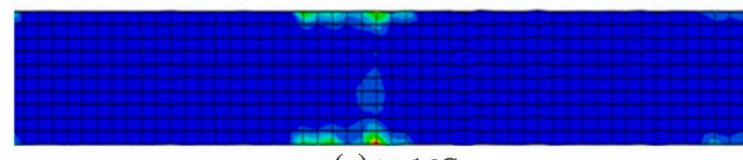

(a) $\Delta t=1^{\circ} \mathrm{C}$

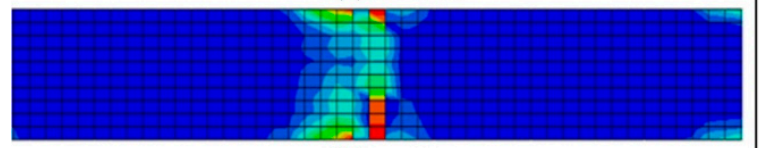

(b) $\Delta t=5^{\circ} \mathrm{C}$

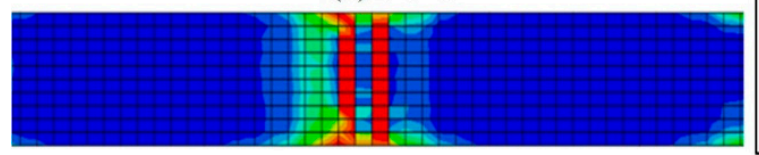

(c) $\Delta t=10^{\circ} \mathrm{C}$

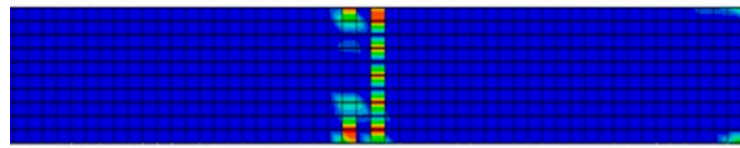

(d) $\Delta=15^{\circ} \mathrm{C}$

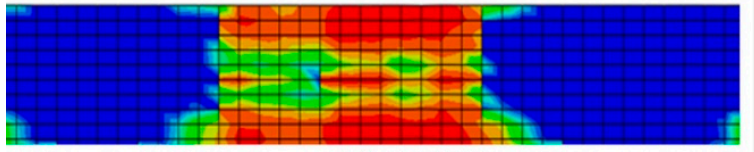

(e) $\Delta t=20^{\circ} \mathrm{C}$

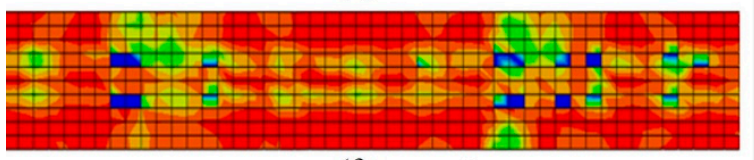

(f) $\Delta t=60^{\circ} \mathrm{C}$

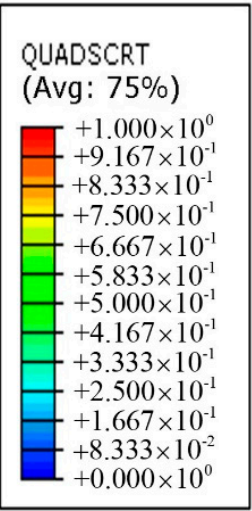

SDEG

(Avg: 75\%)

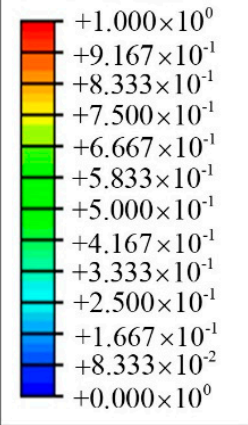

Figure 7. Interface damage evolution process under uniform temperature load.

As shown in the contour of damage indices, the interface under the expansion joint of the base plate was the most vulnerable area under temperature loads. The variation of QUADSCRT and SDEG at the expansion joint with $\Delta t$ is plotted in Figure 8. The variation of interface damage ratio and detachment area ratio with $\Delta t$ is presented in Table 4 . Interface damage ratio is the percentage of damaged area (QUADSCRT $=1$ and SDEG $>0$ ) in the total area. Detachment area ratio is the percentage of delaminated (SDEG $=1$ ) in the total area. When $\Delta t=5.9^{\circ} \mathrm{C}$, QUADSCRT at the expansion joint increased to 1 , suggesting that the interface microcracks started to generate. When $\Delta t$ was $19.2{ }^{\circ} \mathrm{C}$, interface macrocracks initiated and propagated. From the initiation of interface microcracks to the initial debonding of the adjacent layers, the temperature increase was about $13.3^{\circ} \mathrm{C}$. The temperature rising range was $45.8^{\circ} \mathrm{C}$ for the macrocracks to expand completely and the whole interface to delaminate.

Then, the interface under the expansion joint of the base plate was selected as the research object - the effect of interface parameters and temperature loads on the interface cracking performance was analyzed. The interface parameters included interfacial shear strength, interfacial shear stiffness, and critical fracture energy, and their values are listed in Table 5 . When analyzing the impact of one parameter, the other parameters, in the middle column of Table 5, are the corresponding values. 


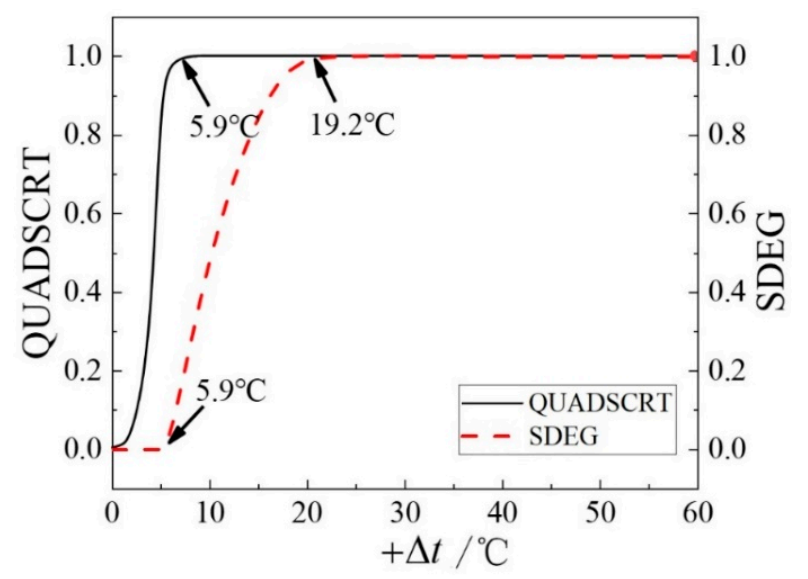

Figure 8. QUADSCRT and SDEG varying with $\Delta t$.

Table 4. Interfacial damage and detachment area ratio.

\begin{tabular}{ccc}
\hline Temperature Rising Range $\left({ }^{\circ} \mathbf{C}\right)$ & Interfacial Damage Area Ratio & Interfacial Detached Area Ratio \\
\hline 5 & 0 & 0 \\
10 & 20 & 0 \\
15 & 40 & 0 \\
20 & 70 & 12 \\
30 & 90 & 43 \\
40 & 95 & 55 \\
50 & 98 & 80 \\
60 & 99 & 92 \\
\hline
\end{tabular}

Table 5. Interface parameters of adjacent CCBP and ACWL.

\begin{tabular}{lccccc}
\hline \multicolumn{5}{c}{ Parameter } & \multicolumn{5}{c}{ Values } \\
\hline Interfacial shear strength $(\mathrm{MPa})$ & 0.04 & 0.06 & 0.10 & 0.50 & 1.0 \\
Interfacial shear stiffness $(\mathrm{MPa} / \mathrm{mm})$ & 0.01 & 0.02 & 0.03 & 0.04 & 0.05 \\
Critical fracture energy $\left(\mathrm{mJ} / \mathrm{mm}^{2}\right)$ & 0.2 & 0.3 & 0.4 & 0.5 & 0.6 \\
\hline
\end{tabular}

The variation curve of the QUADSCRT index at the adjacent joint under different working conditions with the temperature rising range is plotted in Figure 9. As shown in Figure 9a, $\Delta t$ needed for the initiation of interface damage (microcracks) increased with the increase in interfacial shear strength, but $\Delta t$ needed for the initiation of macrocracks was not impacted by the interfacial shear strength. Also, the slopes of the QUADSCRT temperature rising range curves in Figure 9a indicate that the larger the interfacial shear strength, the faster the interfacial damage propagation rate. Increasing the interfacial shear strength is conducive to the stability of the whole structure. $\Delta t$ needed for the initiation of microcracks decreased as the interfacial shear stiffness increased, while $\Delta t$ needed for macrocrack initiation remained unchanged (Figure 9b). These results indicate that an increase in interfacial shear strength makes the interfacial damage (microcrack) more sensitive to the temperature changes, but has a little influence on the initiation behavior of interfacial macrocracks. As shown in Figure $9 c$, with an increase in the critical fracture energy, $\Delta t$ needed for initiation of the interface damage remained unchanged, while $\Delta t$ needed for the macrocracks' initiation increased. One effective way to reduce the sensitivity of the interfacial macrocracks to temperature changes is to increase the interfacial critical fracture energy. 


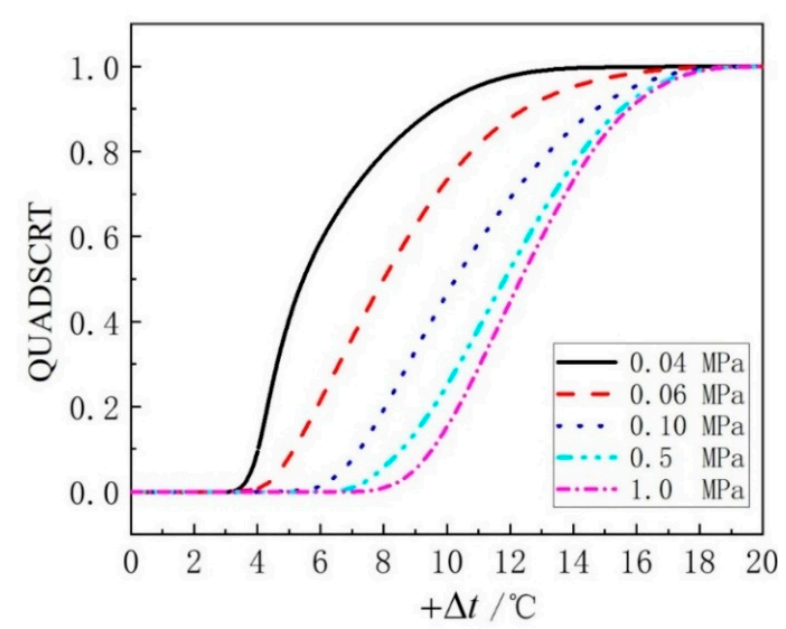

(a)

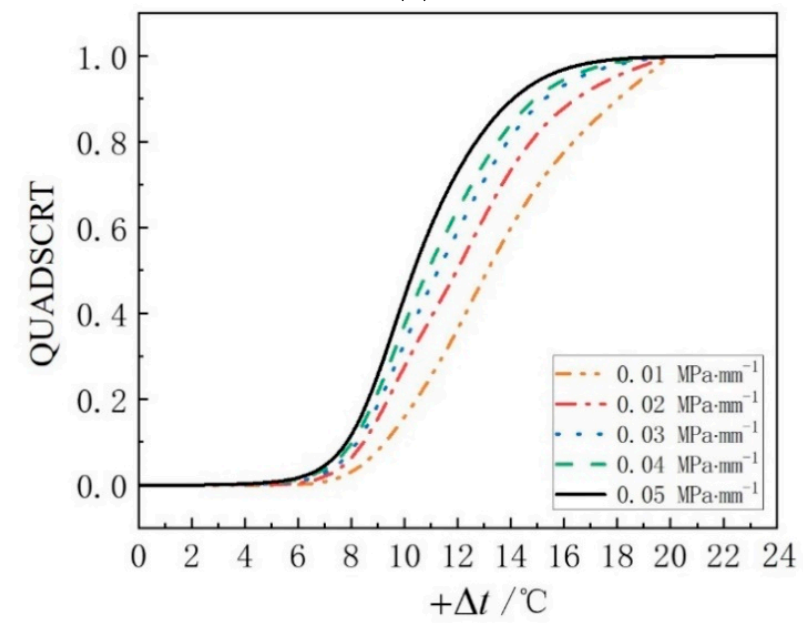

(b)

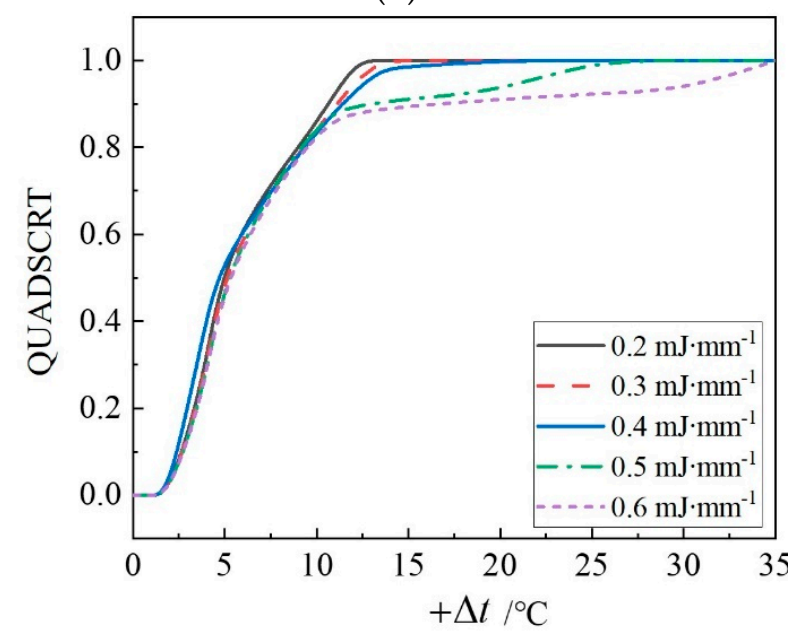

(c)

Figure 9. QUADSCRT- $\Delta t$ curves of different interface parameters: (a) Impact of interfacial shear strength; (b) Impact of interfacial shear stiffness; and (c) Impact of critical fracture energy.

As per the above analysis, the interface with larger interfacial strength and toughness has a smaller damage area. The greater the interfacial stiffness, the stronger the interaction between adjacent layers and the easier the generation of interface damage. Therefore, appropriate material and necessary measures (such as toughening by brushing) should be adopted in the construction 
of asphalt concrete layer to guarantee excellent strength and toughness at the interface, in order to enhance the deformation coordination ability between CCBP and ACWL, especially in the shear direction. During the maintenance stage, patching material with high strength, high toughness, and lower stiffness should be selected. Meanwhile, measures (such as laying geotextiles, etc.) should be taken to reduce the interface stiffness and alleviate the initiation possibility of interface damage at the expansion joint of the base plate, which is more prone to interface damage.

\subsection{Interface Damage Analysis under Gradient Temperature Load}

Because of large annual/daily temperature difference in Northern China and poor thermal conductivity of concrete materials, the seasonal changes in atmospheric temperature can result in a gradient temperature field in the ballastless track. Under the action of gradient temperature, the interface damage caused by the relative displacement trend of the adjacent layers accumulates. Therefore, this section analyzes the evolution process of the interface-bond-slip behavior between ACWL and CCBP under positive and negative gradient temperature loads.

According to the recommended value in the "Code for Design of High Speed Railway" in China (TB10621-2014), the positive temperature gradient load (the upper layer is hotter than the lower layer) was set as $90^{\circ} \mathrm{C} / \mathrm{m}$, and the negative temperature gradient in track slab (the upper layer is colder than the lower layer) was set as $45^{\circ} \mathrm{C} / \mathrm{m}$, respectively. Although the temperature gradient was negligible in the layers that are over $0.2 \mathrm{~m}$ in depth from the track slab surface, $10^{\circ} \mathrm{C} / \mathrm{m}$ was set in the cement base plate for design security. The temperature gradient in layers below the base plate was not set.

The effect of coupled action of gradient and uniform temperature loads on the interfacial characteristics was also analyzed. The details of the simulation cases are listed in Table 6.

Table 6. Details of temperature loads for different simulated cases.

\begin{tabular}{ccc}
\hline Case & Gradient Temperature Load ${ }^{\circ} \mathbf{C} / \mathbf{m}$ & Uniform Temperature Load ${ }^{\circ} \mathbf{C} / \mathbf{m}$ \\
\hline 1 & Positive, 90 & $/$ \\
2 & Negative, 45 & $/$ \\
3 & Positive, 90 & $(+) 5,10,15,20,30,40,50,60$ \\
4 & Positive, 90 & $(-) 5,10,15,20,30,40,50,60$ \\
5 & Negative, 45 & $(+) 5,10,15,20,30,40,50,60$ \\
6 & Negative, 45 & $(-) 5,10,15,20,30,40,50,60$ \\
\hline
\end{tabular}

As shown in Figure 10, in cases 1 and 2, only a few interface microcracks were generated at the expansion joint of the base plate and the damage area was extremely small. The positive/negative gradient temperature load had little effect on the interface between CCBP and ACWL. The transverse and longitudinal shear stress and normal displacement at the interface between CCBP and ACWL in cases 1 and 2 are listed in Table 7. The deformation of the interface was tiny and the stress between the adjacent layers was smaller than the designed strength, which signifies that the ballastless track structure was safe under a $90{ }^{\circ} \mathrm{C} / \mathrm{m}$ positive gradient temperature load and a $45^{\circ} \mathrm{C} / \mathrm{m}$ negative gradient temperature load. 


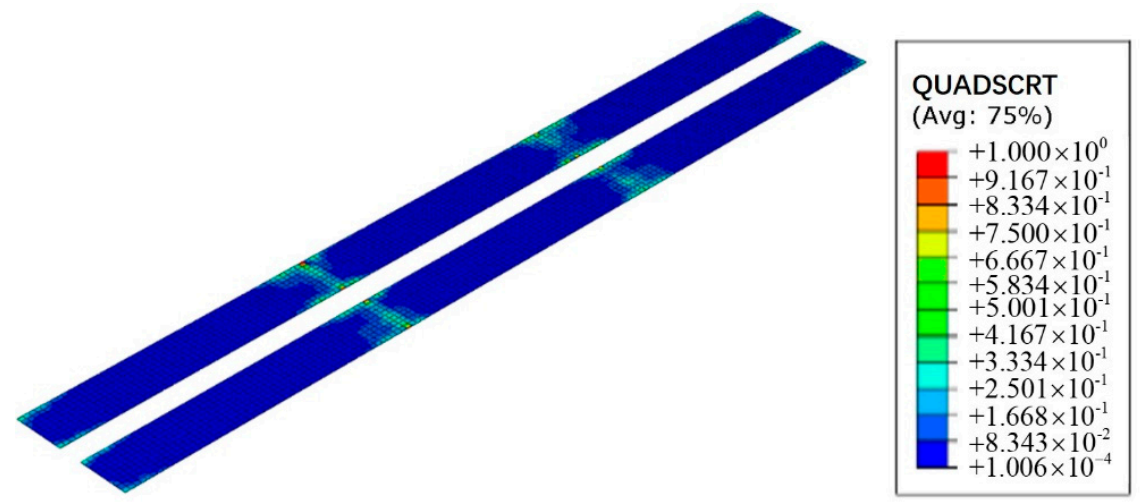

(a) Case 1

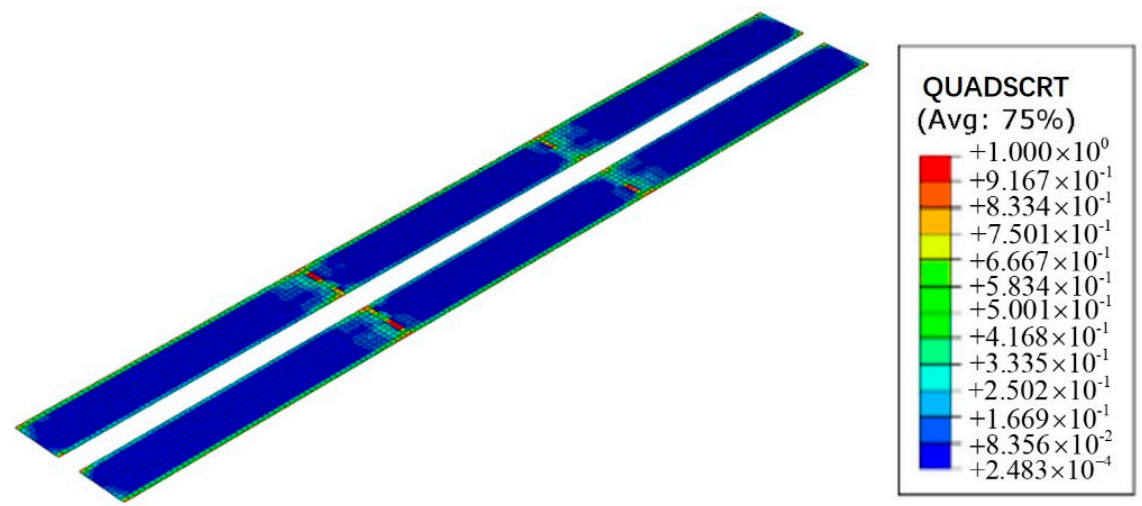

(b) Case 2

Figure 10. Interfacial damage contour under positive gradient temperature load.

Table 7. Interfacial stress and displacement under positive gradient temperature load.

\begin{tabular}{ccccccc}
\hline \multirow{2}{*}{ Case } & \multicolumn{3}{c}{ Stress/MPa } & \multicolumn{3}{c}{ Displacement/mm } \\
\cline { 2 - 7 } & Transverse & Longitudinal & Normal & Transverse & Longitudinal & Normal \\
\hline 1 & $0.021 /-0.026$ & $0.077 /-0.072$ & $0.001 /-0.001$ & $0.002 /-0.002$ & $0.001 /-0.001$ & $0.698 /-0.018$ \\
2 & $0.025 /-0.016$ & $0.067 /-0.064$ & $0.001 /-0.001$ & $0.002 /-0.002$ & $0.001 /-0.001$ & $0.19 /-0.10$ \\
\hline
\end{tabular}

The relationship curves of QUADSCRT/SDEG and temperature rising/dropping range $( \pm \Delta t)$ in cases 3 6 are plotted in Figure 11. As shown in Figure 11a, when the initial temperature load was $90{ }^{\circ} \mathrm{C} / \mathrm{m}$ (positive), the microcracks started to generate when $+\Delta t$ was $5.5^{\circ} \mathrm{C}$ and macrocracks occurred when $+\Delta t=18.8^{\circ} \mathrm{C}$. When the temperature was reduced and the initial temperature gradient was $90^{\circ} \mathrm{C} / \mathrm{m}$ (positive), the microcracks started to generate when the temperature dropping range was $7.7^{\circ} \mathrm{C}$. The interface started to debond when the temperature dropping range was $20.8^{\circ} \mathrm{C}$ (Figure $11 \mathrm{~b}$ ). As depicted in Figure 11c, when the negative gradient temperature load and the global warming load worked together, the interface microcracks started to generate when $-\Delta t$ was $7.4^{\circ} \mathrm{C}$ and the interface started to delaminate when the temperature dropping range was $20.5^{\circ} \mathrm{C}$. As shown in Figure $11 \mathrm{~d}$, when the negative gradient temperature load and the overall cooling load worked together on the structure, the interfacial microcracks started to generate when the temperature dropping range was $5.3^{\circ} \mathrm{C}$ and the macrocracks generated when the dropping range was $18.6{ }^{\circ} \mathrm{C}$. 


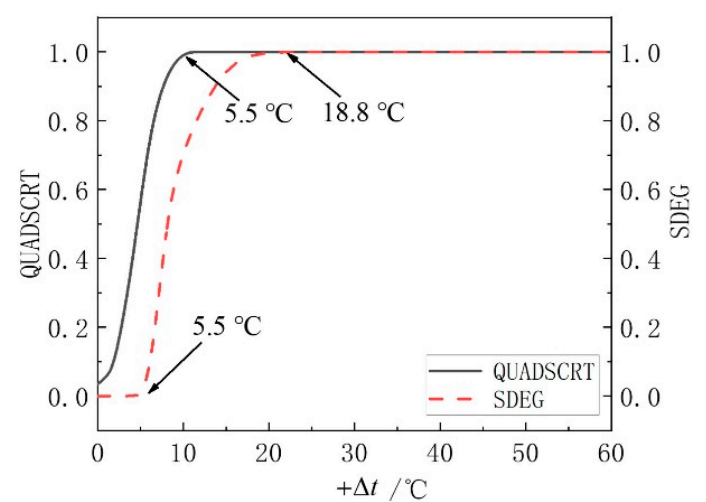

(a) Case 3

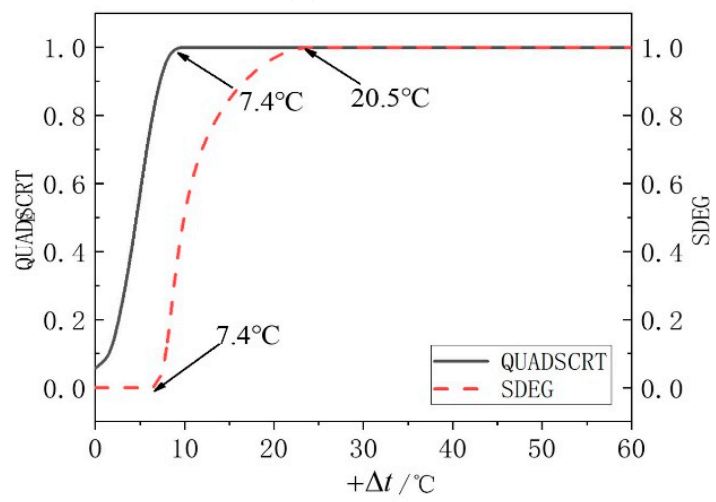

(c) Case 5

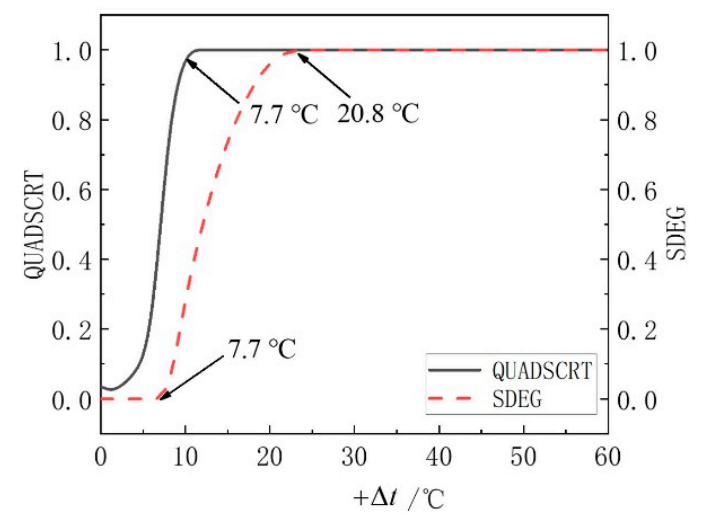

(b) Case 4

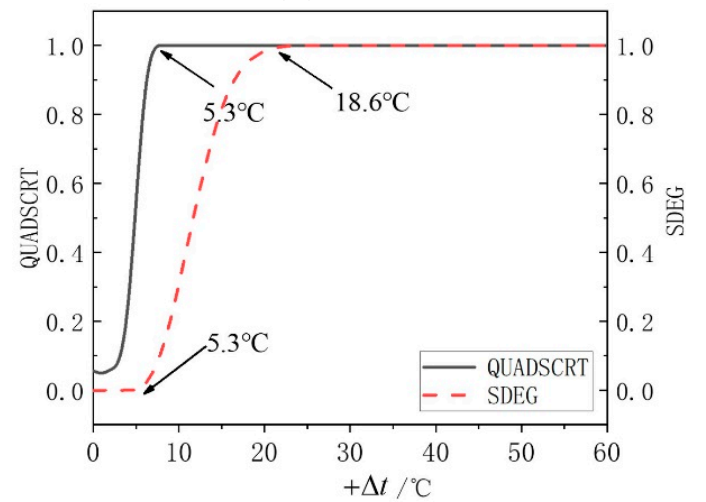

(d) Case 6

Figure 11. Relationship curves between QUADSCRT/SDEG and $\pm \Delta t$ in cases 3 6.

By comparing Figures 9 and 11a,b, the initiation of interface microcracks and interface macrocracks was exacerbated under the combined action of a positive gradient temperature load and global warming load, but they were delayed under the combined action of a positive gradient temperature load and global cooling load. By comparing Figures 9 and 11c,d, the initiation of interface microcracks and interface macrocracks was exacerbated under the combined action of a negative gradient temperature load and global cooling load, but they were delayed when the loading state was a negative gradient temperature load and global cooling load.

\subsection{Dynamic Characteristics of the Ballastless Track with Interface Damage}

The effect of existing interface damage on the safety and stability of high-speed railway operation is worth exploring. In this case, the quasi-static damage analysis of the ballastless track under temperature load was performed first to obtain the initial state of the track structure. Then, the train vibration load was applied on the rails to analyze the dynamic response of the ballastless track with three interface contacting conditions of CCBP and ACWL including the perfect bond state, partly damaged but no slippage state $\left(\Delta t=5{ }^{\circ} \mathrm{C}, 15^{\circ} \mathrm{C}\right)$, and the sliding friction contact state. The tensile strain, vertical deformation in ACWL, and dynamic stress in the surface layer of the road bed were selected as the indices.

In this section, a three-dimensional finite element model of a ballastless track structure containing the rails and fasteners was established. This structure was composed of CHN60 rails, a fastener system, track slab, self-compacting concrete (SCC), CCBP, ACWL, road bed, and soil foundation. The CHN60 rails were modelled by Euler beam element. The fastener system was modelled by spring-damper elements. The vertical and transverse stiffness of the fasteners and pads were $70 \mathrm{KN} / \mathrm{m}$ and $30 \mathrm{KN} / \mathrm{m}$, and the vertical and horizontal damping were $60 \mathrm{KN} \cdot \mathrm{s} / \mathrm{m}$ and $50 \mathrm{KN} \cdot \mathrm{s} / \mathrm{m}$, respectively. The geometries 
and the material parameters of other components and the model constraints were the same as the former model.

The train vibration load is regarded as a periodic moving load and simplified to a sine function, as shown in Equation (5).

$$
F(t)=P_{0}+P_{1} \sin \omega_{1} t
$$

where $F(t)$ is the train vibration load, $P_{0}$ is the static wheel load, $130 \mathrm{KN}, P_{1}$ is the vibration load, $P_{1}=M_{0} a_{i} \omega_{i}{ }^{2}, M_{0}$ is the unsprung mass of the train, $750 \mathrm{~kg}, a_{i}$ is the height of geometric irregularity, $0.6 \mathrm{~mm}, \omega_{i}$ is the circular frequency of the vibrating wavelength, $\omega_{i}=2 \pi v / L_{i}, v$ is the train speed, $350 \mathrm{~km} / \mathrm{h}$, and $L_{i}$ is the wavelength of geometric irregularity curve, $2 \mathrm{~m}$.

The train vibration load was applied on the rails at the joint of the adjacent track slab (case 1) and the center of the base plate (case 2), respectively. The calculation results of dynamic responses are summarized in Table 8.

Table 8. Dynamic characteristics of four interfacial bonding states.

\begin{tabular}{ccccccccc}
\hline Bonding State & $\begin{array}{c}\text { Transverse Tension } \\
\text { Strain }(\mu \varepsilon)\end{array}$ & $\begin{array}{c}\text { Longitudinal } \\
\text { Tension Strain }(\mu \varepsilon)\end{array}$ & $\begin{array}{c}\text { Vertical } \\
\text { Displacement of } \\
\text { Asphalt Layer } \\
\text { Surface (mm) }\end{array}$ & $\begin{array}{c}\text { Vertical Stress on } \\
\text { Unbounded } \\
\text { Aggregate Layer } \\
(\text { KPa) }\end{array}$ \\
\cline { 2 - 10 } & Case 1 & Case 2 & Case 1 & Case 2 & Case 1 & Case 2 & Case 1 & Case 2 \\
\hline Perfect bond & 6 & 5 & 9 & 7 & 0.38 & 0.25 & 7.7 & 4.7 \\
Microcracks' initiation & 87 & 87 & 43 & 41 & 0.33 & 0.24 & 13.3 & 13.3 \\
Partly delaminating & 245 & 240 & 75 & 73 & 0.66 & 0.65 & 43.4 & 43.1 \\
Totally delaminating & 800 & 800 & 450 & 450 & 1.61 & 1.61 & 181 & 180 \\
\hline
\end{tabular}

As shown in Table 8, the dynamic indices at the adjacent joint and the center of base plate were almost the same. The interface contact state had a great impact on the dynamic response of the whole structure under the train loads. Compared with the perfectly bonded state, for the state where few interface microcracks existed, the transverse tension strain of ACWL was about ten times that of the previous state, while the longitudinal tension strain and the vertical stress in the surface layer of subgrade were about 10 times and 2 times that of the previous state, respectively. When the interface was totally unbonded, the transverse and longitudinal tension strain and vertical displacement of asphalt layer surface were about 134, 50, and 24 times that of the original state. The interface damage had a great influence on the dynamic response of the ballastless track.

\section{Conclusions}

To investigate the interface damage initiation, propagation, and delamination process between CCBP and ACWL in ballastless track under temperature loads, a 3D finite model of ballastless track which utilizes a bilinear CZM was introduced in this study. By comparing the full-scale transverse shear test results and simulation results, the bilinear CZM was verified as capable of predicting the initiation and propagation of the interface damage. The interface damage evolution process under uniform and gradient temperature loads and the effect of interface material properties on the interface characteristics was investigated. By setting partly and totally delaminated interface state as the initial conditions, the influence of interface damage on the dynamic response was also analyzed. The main findings can be summarized as follows

(1) It is reasonable to obtain the parameters of CZM from the full-scale transverse shear test and apply them in the numerical simulations of interfacial damage evolution under temperature load.

(2) For the simulated conditions in this work, the microcracks between CCBP and ACWL were initiated when the temperature rising range was $5.9{ }^{\circ} \mathrm{C}$, and the adjacent layers started to delaminate when the heating range was $19.2^{\circ} \mathrm{C}$. When $\Delta t$ exceeded $60^{\circ} \mathrm{C}$, the interface totally delaminated and turned into the slipping contacting state. 
(3) The temperature rising range needed for the interfacial damage initiation was mainly affected by the interfacial shear strength and interfacial shear stiffness, while the delamination of the adjacent layers was mainly affected by the critical fracture energy. The interfacial damage evolution process can be effectively controlled by increase in the interfacial shear stress and the critical fracture energy.

(4) The research on effects of interface contacting state on the dynamic response of the ballastless track indicates that a great interface bond state is crucial for the safety of ballastless track operation.

This interface damage propagation research will help engineers to predict the interface damage propagation process more accurately and optimize the interface safety design of ballastless track structure. To investigate the overall performance of the novel ballastless track, future work will focus on the establishment of a non-linear mechanical model which analyzes the coupling effect of in-layer damage and inter-layer damage.

Author Contributions: Conceptualization, X.C. and D.C.; methodology, X.C. and T.D.; software, Y.Z., and T.D.; validation, T.D. and G.X.; formal analysis, Y.Z., G.X., and T.D.; investigation, Y.Z., G.X., and T.D.; writing一original draft preparation, Y.Z., G.X.; writing-review and editing, X.C. and D.C. All authors have read and agreed to the published version of the manuscript.

Funding: This research was funded by the National Natural Science Foundation of China (No. 51778136, No. 51778140, and 41972299) and the Technology Research and Development Project of China Railway (No. J2019G003).

Acknowledgments: The authors wish to thank the reviewers for their valuable comments and suggestions concerning this manuscript.

Conflicts of Interest: The authors declare no conflicts of interest.

\section{References}

1. Liu, S.; Yang, J.; Chen, X.; Yang, G.; Cai, D. Application of Mastic Asphalt Waterproofing Layer in High-Speed Railway Track in Cold Regions. Appl. Sci. 2018, 8, 667. [CrossRef]

2. Ye, Y.; Xu, G.; Lou, L.; Chen, X.; Cai, D.; Shi, Y. Evolution of Rheological Behaviors of Styrene-Butadiene-Styrene/Crumb Rubber Composite Modified Bitumen after Different Long-Term Aging Processes. Materials 2019, 12, 2345. [CrossRef] [PubMed]

3. Rose, J.G.; Teixeira, P.F.; Ridgway, N.E. Utilization of asphalt/bituminous layers and coatings in railway trackbeds-a compendium of international applications. In Proceedings of the 2010 Joint Rail Conference, New York, NY, USA, 27-29 April 2010; pp. 239-255.

4. Teixeira, P.F.; López Pita, A.; Ferreira, P.A. New Possibilities to Reduce Track Costs on High-Speed Lines Using a Bituminous Sub-Ballast Layer. Int. J. Pavement Eng. 2010, 11, 301-307. [CrossRef]

5. Rose, J.G. Selected In-Track Applications and Performances of Hot-Mix Asphalt Trackbeds. In Proceedings of the 2013 Joint Rail Conference, Knoxville, TN, USA, 15-18 April 2013. V001T01A017.

6. Lee, S.H.; Choi, Y.T.; Lee, H.M.; Park, D.W. Performance evaluation of directly fastened asphalt track using a full-scale test. Constr. Build. Mater. 2016, 113, 404-414. [CrossRef]

7. Sysyn, M.; Nabochenko, O.; Kovalchuk, V.; Gruen, D.; Pentsak, A. Improvement of Inspection System for Common Crossings by Track Side Monitoring and Prognostics. Struct. Monit. Maint. 2019, 6, 219-235.

8. Zhou, J.; Chen, X.; Fu, Q.; Xu, G.; Cai, D. Dynamic responses of asphalt concrete waterproofing layer in ballastless track. Appl. Sci. 2019, 9, 375. [CrossRef]

9. Ferreira, P.A.; López-Pita, A. Numerical Modelling of High Speed Train/Track System for the Reduction of Vibration Levels and Maintenance Needs of Railway Tracks. Constr. Build. Mater. 2015, 79, 14-21. [CrossRef]

10. Teixeira, P.F.; Ferreira, P.A.; Pita, A.L.; Casas, C.; Bachiller, A. The Use of Bituminous Subballast on Future High-Speed Lines in Spain: Structural Design and Economical Impact. Int. J. Railw. 2009, 2, 1-7.

11. Lee, S.H.; Park, D.W.; Vo, H.V.; Fang, M. Analysis of asphalt concrete track based on service line test results. Constr. Build. Mater. 2019, 203, 558-566. [CrossRef]

12. Yu, Z.; Connolly, D.P.; Woodward, P.K.; Laghrouche, O. Settlement behaviour of hybrid asphalt-ballast railway tracks. Constr. Build. Mater. 2019, 208, 808-817. [CrossRef]

13. National Railway Administration of China. Code for Design of High-Speed Railway, TB10621-2014; China Railway Publishing House: Beijing, China, 2014. (in Chinese) 
14. Dai, G.; Su, M. Full-scale field experimental investigation on the interfacial shear capacity of continuous slab track structure. Arch. Civ. Mech. Eng. 2016, 16, 485-493. [CrossRef]

15. Zhu, S.; Wang, M.; Zhai, W.; Cai, C.; Zhao, C.; Zeng, D.; Zhang, J. Mechanical property and damage evolution of concrete interface of ballastless track in high-speed railway: Experiment and simulation. Constr. Build. Mater. 2018, 187, 460-473. [CrossRef]

16. Ren, J.; Wang, J.; Li, X.; Wei, K.; Li, H.; Deng, S. Influence of cement asphalt mortar debonding on the damage distribution and mechanical responses of CRTS I prefabricated slab. Constr. Build. Mater. 2020, 230, 116995. [CrossRef]

17. Song, L.; Liu, H.; Cui, C.; Yu, Z.; Li, Z. Thermal deformation and interfacial separation of a CRTS II slab ballastless track multilayer structure used in high-speed railways based on meteorological data. Constr. Build. Mater. 2020, 237, 117528. [CrossRef]

18. Stoffels, S.M.; Kwanda, F.D. Determination of the coefficient of thermal contraction of asphalt concrete using the resistance strain gage technique. J. Assoc Asph. Paving. Technol. 1996, 65, 73-93.

19. Chen, J.; Zhang, M.; Wang, H.; Li, L. Evaluation of thermal conductivity of asphalt concrete with heterogeneous microstructure. Appl. Therm. Eng. 2015, 84, 368-374. [CrossRef]

20. Asadi, I.; Shafigh, P.; Hassan, Z.F.B.A.; Mahyuddin, N.B. Thermal conductivity of concrete-A review. J. Build. Eng. 2018, 20, 81-93. [CrossRef]

21. Tong, F.; Gao, L.; Cai, X.; Zhong, Y.; Zhao, W.; Huang, Y. Experimental and Theoretical Determination of the Frost-Heave Cracking Law and the Crack Propagation Criterion of Slab Track with Water in the Crack. Appl. Sci. 2019, 9, 4592. [CrossRef]

22. Shen, Q.; Chen, W.; Liu, C.; Zou, W.; Pan, L. The Tensile Strength and Damage Characteristic of Two Types of Concrete and Their Interface. Materials 2020, 13, 16. [CrossRef]

23. Cao, S.; Yang, R.; Su, C.; Dai, F.; Liu, X.; Jiang, X. Damage mechanism of slab track under the coupling effects of train load and water. Eng. Frac. Mech. 2016, 163, 160-175. [CrossRef]

24. Zhu, S.; Cai, C. Interface damage and its effect on vibrations of slab track under temperature and vehicle dynamic loads. Int. J. Non-Linear Mech. 2014, 58, 222-232. [CrossRef]

25. Liu, G.; Bao, H.; Tang, K. Damage prediction in notched fiber-reinforced composite laminates. Comp. Inter. 2016, 24, 279-290. [CrossRef]

26. Hu, J.; Liu, G.; Zhao, R. Research on Damage of CRTS I Double Block Ballastless Track Bed Slab under Temperature Load. China Railw. Sci. 2013, 10, 84-88.

27. Wang, Q.; Zhang, J.; Meng, F.; Chen, X.; Chen, J. Simulation of train vibration load on the subgrade testing model of high-speed railway. J. Vib. Shock. 2013, 32, 43-46, 72. 